\section{Interdisciplinaridade e promoção da saúde: o papel da antropologia. Algumas idéias simples a partir de experiências africanas $e$ brasileiras*}

\section{Interdisciplinarity and health \\ promotion: the role of \\ anthropology. Some simple ideas based on African and Brazilian experiences}

\section{Claude Raynaut}

\section{Antropólogo}

Diretor de Pesquisa e Diretor do Laboratório

Sociétés, Santé, Développement CNRS UMR 5036

Université Victor Segalen de Bordeaux 2, case 71

146, rue Léo-Saignat

33076 Bordeaux cedex France

raynaut@u-bordeaux2.fr

* Apresentado como Palestra no V Congresso Brasileiro de Epidemiologia. Curitiba, PR, Brasil. 23-27 de março de 2002.
A interdisciplinaridade entre as ciências sociais e as disciplinas médicas é, sem dúvida, um dos requisitos mais freqüentemente citados no tocante à abordagem dos problemas de saúde pública, bem como àqueles que se colocam em um plano individual.

Como fazer cooperar disciplinas que, como a epidemiologia, tentam entender a maneira como as doenças se espalham no seio de amplos conjuntos populacionais ou como elas acometem de maneira diferente várias categorias de população dentro desses conjuntos, com disciplinas que estudam como esses conjuntos são estruturados, funcionam, se transformam em função se não de "leis", pelo menos de algumas regularidades, necessidades próprias, como sistemas sociais organizados?

Como fazer com que as disciplinas clínicas que lidam com pessoas doentes, pretendendo achar soluções para as causas de seu sofrimento físico, integrem o fato de a essência da pessoa humana ir muito além do seu corpo biológico - sendo ela um ser que pensa, imagina, simboliza, vive tanto de afetos e fantasmas quanto de alimentos materiais? Como fazer com que aqueles especialistas cuja atuação se dirige aos indivíduos seja para curá-los ou para educá-los - admitam o fato de cada pessoa ser inserida em redes, estruturas, formas de pensamento coletivas que até certo ponto marcam e orientam seu comportamento?

Mas o problema não se coloca apenas do lado das disciplinas médicas e biológicas que teriam que aceitar os lados imateriais e sociais da realidade humana. A dificuldade reside também em como conseguir que as ciências psicológicas e sociais admitam que o ser humano não é constituído somente de um espírito, mas também de um corpo. Como conseguir que elas admitam também que as sociedades humanas não podem ser analisadas apenas na sua dimensão cultural, levando unicamente em conta suas representações, seus modelos de comportamento, o modo como elas organizam as relações entre seus membros? Como conseguir que aquelas ciências humanas integrem essa evidência de que os sistemas sociais só existem 
porque se arraigam em uma realidade biológica: a dos corpos dos seus membros?

Então, o desafio fundamental é tentar restituir, ainda que de maneira parcial, o caráter de totalidade do mundo real dentro do qual e sobre o qual todos nós pretendemos atuar. Totalidade - a palavra surge cada vez que se fala de interdisciplinaridade! Claro que o mundo real, na sua essência, é total. Ele é feito de inter-relações, interações entre os muitos elementos que o compõem. Ele não conhece fronteira estanque. Mas o paradoxo é o seguinte. Essa totalidade do mundo, sua unicidade, foi uma das primeiras maneiras em que o pensamento humano tomou consciência do universo e da posição do homem no universo. Através do pensamento mítico, das filosofias antigas e até das religiões, muitas foram as maneiras de se apreender esta Unicidade.

A novidade que relacionou o pensamento científico a estas formas antigas de pensamento foi justamente aceitar dividir o mundo em facetas, níveis de organização diferentes e tentar desenvolver instrumentos específicos - conceitos, definições de objetos, métodos de observação - para tentar explicar os fenômenos observados dentro dos limites assim definidos. Foi este próprio reducionismo - este esforço de abstração no próprio sentido da palavra - que capacitou a produção de um conhecimento que permitisse uma ação mais decisiva sobre o mundo. Isso quer dizer que o recorte do real pelas disciplinas foi o movimento histórico do pensamento humano que viabilizou o surgimento e o desenvolvimento do pensamento científico. De certa forma, isto quer dizer que a existência das disciplinas e a possibilidade de pensar o mundo cientificamente são inseparáveis.

Por outro lado, no decorrer da história da construção das ciências perdeu-se a consciência do caráter formal, artificial e às vezes provisório desses recortes. Mais do que ângulos de representação do universo, espaços particulares onde os poderes da mente humana possam se exercer, o recorte disciplinar, outrora instrumento metodológico para organizar o pensamento, transformou- se em partição em territórios, cada vez mais exclusivos um do outro. As fronteiras disciplinares serviram para construir divisões institucionais - nas universidades principalmente - que se tornaram progressivamente redes de interações privilegiadas, quadro de afirmação de identidade intelectual e, por fim, territórios de poder. O sistema educativo reforçou e cristalizou o que era no início uma diversidade epistemológica nas abordagens do real. Um aluno de medicina no final do seu currículo sabe muito pouco, senão nada, das dimensões sociais dos problemas de saúde que ele vai enfrentar. Sem falar nos alunos de ciências sócias, para quem o corpo humano simplesmente não existe, senão como objeto de modelos e representações sociais. No decorrer do último século, a evolução do mundo acadêmico ocorreu no sentido de uma crescente especialização que tornou cada vez mais difícil a comunicação entre as disciplinas. Os intercâmbios entre os grupos e os departamentos nas estruturas de ensino e de pesquisa ficaram cada vez mais escassos.

Mas tal fragmentação não dá conta da realidade encontrada na hora de tentar responder concretamente aos problemas da vida real. Claro que, dentro de um hospital, dá para reduzir uma pessoa doente quase que unicamente ao seu corpo - simples objeto de manipulações e tratamentos. Esquecendo-se de quem ela é, de onde ela vem, qual é seu entorno familiar e social. Se tudo correr bem, ela vai sair curada, mas o que vai acontecer quando ela voltar ao seu ambiente de vida habitual? Aqui, não são mais técnicas médicas que podem segurar a manutenção de um bom estado de saúde. São medidas de prevenção que reclamam a participação ativa da própria pessoa, mas também, muitas vezes, daquelas que compartilham o seu espaço de vida ou cujas atuações e decisões determinam suas condições materiais de vida. Bem se sabe que até nos países mais desenvolvidos, e ainda mais em um país como o Brasil, a questão das desigualdades, das injustiças, é um problema fundamental que tem de ser resolvido para que o estado de saúde da população possa melho- 
rar. Mas já se sabe que não é com técnicas médicas que serão eliminadas as raízes da pobreza e da injustiça.

Confrontados com essas realidades, muitos são aqueles - tanto no âmbito das disciplinas de saúde quanto das ciências sociais - que tentaram desenvolver outros enfoques menos fragmentados, mais abertos à diversidade e à complexidade das dimensões encontradas no cotidiano. Saúde comunitária, saúde da familia, epidemiologia social, são, do lado das disciplinas de saúde, algumas das correntes que tentam fazer esse esforço de síntese. Do lado das ciências sociais, vários trabalhos de antropologia e de sociologia da saúde buscam também utilizar seus instrumentos para responder a problemas de saúde específicos.

Para retomar minha colocação inicial, a interdisciplinaridade se impõe cada vez mais como uma exigência imprescindível para se abordar as questões relativas à saúde das populações e dos indivíduos.

Mas como passar da afirmação de uma exigência geral para uma prática concreta? A questão está em aberto. Alguns pensam que o objetivo é acabar com as divisões entre as disciplinas, formar novos cientistas interdisciplinares capazes de abarcar, cada um, a totalidade dos aspectos da realidade. Homens ou mulheres "orquestras" que pudessem tocar, cada um, todos os instrumentos da análise científica. O modelo ideal de Leonardo da Vinci foi um exemplo de tal saber enciclopédico. Mas foi o resultado do encontro entre a mente de um gênio e um certo estado do desenvolvimento das ciências. Nem todos nós somos gênios e, além disso, a ciência de hoje não é mais aquela da Renascença! Segundo a minha experiência, o risco que traz consigo a pretensão de formar homens-orquestra é acabar fabricando criaturas tipo Frankenstein, feitas de pedaços mal costurados e desajeitadas, sem nenhuma competência sólida nos vários domínios da sua formação.

Conforme o princípio que norteou a concepção do doutorado em Meio Ambiente e Desenvolvimento que criamos há quase dez anos na Universidade Federal do Paraná, o segredo da interdisciplinaridade reside na competência acertada de cada especialista na sua disciplina, mas com o corolário de uma tomada de consciência dos limites da representação da realidade que ele constrói com seus conceitos e instrumentos metodológicos. Aquela consciência conduz à vontade de ultrapassar esses limites graças a trocas de questionamento e de informações com outros especialistas que possuem os conceitos e instrumentos idôneos para analisar outras facetas da realidade ${ }^{1,2}$.

Segundo esta perspectiva, uma interdisciplinaridade realista e eficiente se constrói: - sobre a consciência da relatividade e dos limites da cada campo disciplinar;

- sobre uma boa informação a respeito do que outras disciplinas podem trazer na construção de um conhecimento mais amplo da realidade;

- sobre a vontade e a capacidade de fazer trocas acima das fronteiras disciplinares. Partindo dessas reflexões gerais e preliminares, eu queria orientar esta palestra em função da seguinte interrogação: O que a antropologia pode trazer, em colaboração com disciplinas de saúde pública, e em particular a epidemiologia, para a elaboração de um saber que possa ser útil para tentar resolver problemas de saúde em situações de desenvolvimento? Assim fazendo, vou me basear, antes de tudo, na minha experiência pessoal, a experiência concreta de um pesquisador. Isto posto, quero enfatizar o fato da minha fala atual ser apenas a expressão de uma visão e de uma experiência pessoais. Visão e experiência de alguém que lutou grande parte da sua vida para tornar realidade a utopia da interdisciplinaridade.

Para resumir e simplificar, vou insistir em duas dimensões da contribuição da antropologia para a compreensão de qualquer aspecto da existência concreta de uma sociedade e das dinâmicas que fazem esta sociedade mudar e se transformar frente a eventos exteriores. São dimensões fundamentais - eu diria fundadoras - da disciplina. Mas se aplicam perfeitamente à abordagem dos problemas de saúde em colaboração com disciplinas como saúde pública ou epidemiologia. 
O seres humanos e as sociedades: produtores de sentido

Quando a antropologia aborda um problema particular, ela cuida sobretudo de não desvencilhar os aspectos imateriais, digamos culturais, da realidade analisada daqueles que estão mais ligados às dimensões materiais. A característica definidora do ser humano, comparado aos outros seres vivos no mundo, é o fato de ele ser produtor de sentido. Na sua relação com o mundo material, no quadro de qualquer experiência concreta, em particular daquela das doenças, ele introduz a distância do pensamento. Ele representa o que está acontecendo em função dos seus quadros de pensamento: quadros que se compõem de saberes, crenças, símbolos, valores e modelos éticos.

Esta construção de sentido é o resultado de processos individuais e decorre da própria história de cada um. Mas é também o produto de uma cultura coletiva que imprime sua marca nas representações dos membros de um grupo ou de uma sociedade.

Ela é, enfim, o reflexo de um certo estado das relações sociais, dos interesses, das relações de poder ou de dependência, que procuram se manter ou se desfazer, graças às explicações que são atribuídas aos fatos materiais. Foi o antropólogo francês Marcel Mauss que criou o conceito de "fato social total" para designar aqueles momentos, aqueles acontecimentos coletivos, onde se pode perceber as interligações estreitas existentes entre a materialidade e a imaterialidade da vida de uma sociedade. Acho esta uma das grandes contribuições da antropologia para a análise do social.

Vamos ver agora como este enfoque da disciplina antropológica se aplica a um dos maiores problemas de saúde pública do continente africano. Quero falar da epidemia de aids. Sabe-se que os países do sul do Saara constituem a região do mundo mais afetada por este flagelo ${ }^{3}$. O ONUSIDA estimava que, no ano 1999, dentre as 34 milhões de pessoas seropositivas em todo o mundo, mais de 26 milhões moravam na África ${ }^{4}$. Há lugares, geralmente cidades, na África do Sul, em
Botswana ou em Zâmbia, onde mais de 30\% dos adultos entre20 e50 anos são soropositivos. Em um país como a Costa do Marfim - um dos menos pobres do continente - não são encontrados picos de prevalência tão altos nas cidades, mas, por outro lado, as áreas rurais são duramente acometidas, de modo que se avalia hoje que mais de $10 \%$ da população total dos adultos do país são soropositivos ${ }^{5}$. Valores semelhantes não se acham em todas as partes do continente, mas a ameaça paira sobre todos os países e nenhum lugar está incólume. Isso dá uma idéia da amplitude do choque que constitui a epidemia.

Em muitos lugares, a presença de pessoas doentes na família, na vizinhança, na rede de amigos, faz doravante parte da experiência quotidiana. Já em 1992, quando eu trabalhava em Kigali, capital de Ruanda, país que passou depois por um outro tipo de drama, a guerra civil, $33 \%$ dos adultos - homens e mulheres - eram soropositivos. A faixa mais ativa, mais produtiva, da população urbana estava assim dizimada. Toda a vida cotidiana tinha que se organizar em torno dessa realidade. Com as doenças dos pais e das mães, todo o peso da sobrevivência ficava nos ombros dos outros parentes, dos avós, dos filhos mais velhos. Mas a solidariedade familiar e social não podia enfrentar a intensidade da demanda de apoio. Além disso, reinava o pavor da contaminação, que conduzia muitas vezes à rejeição das pessoas que apresentavam sinais, reais ou supostos, da presença da doença. Daí surgiam tensões, conflitos, abandonos, até tentativas das pessoas cuja saúde estava ainda boa para recuperar os bens das pessoas doentes. Traço esta breve descrição de uma situação dramática só para mostrar a intensidade do choque que representa a epidemia para as populações que ela ataca com tanta violência ${ }^{6}$.

Diante desta situação sanitária extrema, mas também em um âmbito mais amplo, frente à ameaça geral de alastramento da pandemia no continente, qual o tipo de análise que a antropologia, com seus quadros teóricos e seus métodos, pode desenvolver para ajudar a conceber e implementar respostas adequadas? 
Quais foram as orientações públicas adotadas desde o final dos anos 80 para tentar deter a propagação explosiva da pande$\mathrm{mia}^{7}$ ? Conforme as direções impostas pelos peritos do Global AIDS Programme da OMS, foi decidido organizar grandes campanhas de informação e de distribuição de preservativos. Os dados fornecidos pelos primeiros estudos epidemiológicos mostraram em primeiro lugar que o principal fator de propagação do vírus nas condições locais eram as relações heterossexuais. Eles mostraram também que havia populações mais expostas à contaminação: as prostitutas, entre as quais se encontravam taxas de prevalência de até $80 \%$; migrantes e pessoas cuja profissão acarretava a necessidade de viagens e deslocamentos freqüentes, tais como comerciantes e motoristas de caminhão ${ }^{8}$.

Todas as campanhas de informação foram organizadas em função desses achados e também a partir de uma visão muito simplificada da maneira como os comportamentos humanos se constróem. Visão muito próxima do paradigma do homo economicus. Conforme este modelo, o indivíduo é um centro de decisão racional: ele recebe informações e, segundo estas, faz um cálculo do balanço entre custo/beneficio e toma a decisão que vai reduzir os custos e maximizar as vantagens. Então, sendo informado de que a multiplicação das relações sexuais com parceiros diferentes aumenta o risco de contaminação, ele vai ficar com um parceiro só ou utilizar regularmente preservativos com seus vários parceiros. Ele será muito mais impelido a tomar estas decisões porque terá consciência das conseqüências terríveis de uma contaminação que não tem remédio nenhum - o que era verdade até meados dos anos 90, mas que permanece verdade na África, pela falta de acesso aos remédios.

Partindo deste modelo, as campanhas de informação foram organizadas da seguinte maneira:

- Em primeiro lugar, apresentar do modo mais dramático possível as conseqüências da doença: a aids mata, não tem remédio, os sofrimentos da doença são terríveis. Os cartazes apresentavam imagens violentas do estado físico das pessoas doentes.

- Em segundo lugar, insistir na responsabilidade de comportamentos sexuais errados na propagação do vírus: as imagens, os discursos, apontavam a culpa das prostitutas e dos homens que tinham um comportamento sexual descontrolado - em particular, os jovens migrantes, os motoristas, todas as categorias que os estudos epidemiológicos haviam designadas como mais acometidas.

O sucesso dessas campanhas foi muito aquém das expectativas. A propagação da epidemia no continente continuou com um ritmo exponencial. E isso apesar de os dados básicos sobre a aids e sobre os modos de contaminação serem corretamente divulgados entre a população. Esta população não se comportou conforme o modelo teórico do balanço entre custo e beneficio que os promotores das campanhas supunham.

O que aconteceu?É aqui que uma análise de tipo antropológico pode ajudar a entender a situaçãa $0^{9-12}$. Diante desta ameaça de saúde totalmente nova e desconhecida, as sociedades e as culturas locais não se comportaram como um mero conjunto de consumidores de informações oriundas de fora; elas entraram em um processo coletivo de construção de sentido, a fim de tornar uma novidade tão radical e assustadora algo que pudesse ser pensado. Fizeram isso recuperando as informações trazidas pelas campanhas públicas, mas as reinterpretando conforme os processos de atribuição de sentido já existentes dentro de suas culturas, e também em função de todos os outros embates pendentes nas suas sociedades enquanto a epidemia da aids se instalava.

Essas culturas já tinham quadros para interpretar os eventos que trazem danos e infelicidade - entre os quais as doenças e a morte. Esses eventos não podem ser percebidos como mero resultado do acaso ou do encadeamento de fatores físicos. Eles são as conseqüências de razões escondidas, principalmente a perturbação da ordem religiosa e social devido a comportamentos desviantes, mas também podem ser a manifes- 
tação da malevolência dos homens, bem como das entidades supranaturais. A interpretação pela desordem e as interpretações da malevolência são as mais freqüentes nessas sociedades, assim como em muitas sociedades quando elas se colocam em uma postura defensiva. Nossas sociedades, as da Europa, também têm este tipo de reação quando enfrentam dificuldades e situações de crise: as queixas relativas à falta de ordem, as explicações racistas ou a interpretação da malevolência de grupos que agem às escondidas são muito freqüentes. Por serem menos místicas, elas não são mais racionais.

Frente a todas as informações derramadas pelas campanhas públicas, o primeiro trabalho das sociedades africanas foi buscar dentre as doenças mais graves que elas já tinham classificado dentro da suas nosologias, aquelas mais próximas dos sintomas da aids. Sendo essas doenças mais graves geralmente associadas a causas místicas e a operações de feiticeiros, a aids foi muitas vezes interpretada como uma nova forma dessas doenças tradicionais. Mas uma interpretação antropológica que só enfatizaria a recuperação pela tradição não pode dar conta da complexidade dos fenômenos de construção de sentido que vêm operando em torno da aids. As sociedades africanas não são mais sociedades "tradicionais". Elas estão totalmente inseridas dentro do mundo contemporâneo e têm que enfrentar problemas relativos a essa inserção.

Uma questão fundamental à qual elas se esforçam para responder diz respeito à posição de fraqueza, submissão e dependência que ocupam dentro de conjuntos políticos e econômicos mais amplos: o estado nacional dominado pelos países ricos, em particular os antigos colonizadores. Uma das interpretações que circulou entre muitos países africanos e entre muitas sociedades locais (apesar das grandes diferenças de culturas tradicionais) foi de a aids ser o resultado de um esquema dos países ricos destinado a enfraquecer e explorar ainda mais os países africanos. Para alguns, a aids não existe; é pura criação da malevolência internacional, em particular para impor o uso dos preservati- vos e diminuir o crescimento populacional do continente - reduzindo assim a sua riqueza principal: seus homens. Até agora, o presidente da África do Sul - um dos países mais acometidos pela epidemia - defende essa idéia. Outros não negam a existência da aids, mas atribuem sua origem à introdução do vírus - proposital ou acidental - pelos ocidentais (europeus e norte-americanos). Essas interpretações da aids se inserem dentro de um esforço mais amplo para pensar uma situação social, política e econômica, mas conduzem muitas pessoas a rechaçar as recomendações relativas à proteção contra a contaminação.

Mas, além desse esforço de análise sócio-política, as sociedades africanas tinham que tentar interpretar as grandes mudanças internas que aconteciam na sua própria existência e na sua organização. Para resumir e simplificar de uma maneira extrema podese dizer que as maiores transformações aconteceram em três domínios distintos.

\section{As relações entre os homens e as mulheres}

Apesar de permanecerem até agora submetidas ao poder dos homens (pais, irmãos, maridos) muitas mulheres africanas conquistaram de fato, durante as últimas décadas, espaços de atuação e um certo grau de autonomia que não desfrutavam antes. Isso é, por exemplo, o resultado dos grandes fluxos de migração que levaram os homens para as cidades, deixando as mulheres na aldeia assumindo responsabilidades que antes cabiam aos homens. Algumas delas aproveitaram a situação para estabelecer um certo poder econômico e até mesmo para escapar da autoridade dos pais e levar uma existência mais livre. O que se chama de "prostituição" é, às vezes, a manifestação da vontade de superar a sua dependência dos homens e de negociar pessoalmente o acesso ao seu corpo.

\section{As relações entre os mais velhos e os jovens}

Tradicionalmente, em muitas sociedades, os jovens estavam sob a responsabilidade dos pais, dos tios, de homens da geração acima 
da sua. A sua margem de autonomia era muito reduzida: para se casarem, para terem acesso a terra, para desempenharem qualquer atividade produtiva, eles deviam de um modo ou de outro - conseguir a autorização dos mais velhos. A introdução de uma economia de mercado, a oferta de emprego assalariado por empresas privadas ou públicas, a possibilidade de fugir para as cidades ou para outros países vizinhos e ganhar dinheiro, abriu novos espaços de autonomia para os mais jovens. Os pais começaram a perder parte da sua autoridade sobre os jovens.

\section{As relações entre populações de origens diferentes}

As migrações e os deslocamentos de populações que viviam antes mais ou menos distantes ou alheias uma da outra, as migrações para as cidades e também os movimentos de ocupação de espaços rurais livres fizeram com que populações com tradições, língua e modos de vida distintos tivessem de conviver em espaços próximos. Devemos precisar que, de maneira geral, a situação fundiária lá é totalmente diferente da que encontramos no Brasil. Na maioria dos países - a não ser o Quênia, o Zimbabwe e a África do Sul - não há grandes latifúndios e, até recentemente, havia grandes extensões de terras devolutas. Contudo, essa nova convivência entre grupos com interesses e modos de vida diferentes criou freqüentemente reações de rejeição por parte dos primeiros ocupantes em relação aos recém-chegados. Isso criou tensões e conflitos.

Todas as informações recebidas sobre a aids, seus modos de transmissão e as categorias de população cujo comportamento era designado como principal responsável por sua propagação rápida, foram reinterpretadas e reutilizadas em função das tensões e conflitos conhecidos por essas sociedades envolvidas em processos rápidos de transformação. Na medida que as prostitutas eram apresentadas como a fonte principal de origem do vírus e que os migrantes e os homens cujas profissões obrigavam a vi- agens freqüentes apareciam como os principais veículos de sua propagação, essas informações alimentaram, dentro das comunidades locais, um discurso crítico sobre o papel que a perda de controle sobre as mulheres e os jovens, bem como a chegada de muitos estrangeiros, desempenhava no alastramento da epidemia. A solução era, então, restabelecer o controle das categorias dominantes sobre a sociedade, voltar a uma ordem perdida.

No final, seguindo vários caminhos, as informações fornecidas pelas campanhas públicas não foram interpretadas pelas populações de acordo com o modelo teórico elaborado pelos promotores dessas operações. Elas entraram em um jogo complexo de "metabolização", por parte das próprias culturas locais, em função de seus quadros tradicionais de representação dos eventos danosos e das doenças, mas também em relação aos muitos problemas que elas têm que resolver na realidade de hoje. O resultado disso foi que a maioria dos indivíduos que receberam as mensagens de propaganda negou a realidade do risco ou projetou para os outros a responsabilidade das mudanças de comportamento a serem operadas: as mulheres, os estrangeiros, os jovens, os urbanos. Cada um foi encontrando um responsável, conforme sua própria situação.

Mas todo esse processo de reinterpretação cultural e social de uma pandemia que se revela cada vez mais real e assustadora só conseguiu permanecer operando devido às grandes opções que foram feitas desde o início para organizar a luta contra a epidemia. Em muitos países fora da África a divulgação de informações sobre a aids foi acompanhada da implantação de uma estrutura de Testing and Counselling, anônima e gratuita, que permitia que cada pessoa com dúvidas sobre seu estado sorológico pudesse se informar dele e receber conselhos para organizar sua vida e suas relações pessoais em função do resultado. Além disso foram organizados esquemas para cuidar das pessoas doentes, tanto do ponto de vista médico como do ponto de vista psicológico e material. Nada disso aconteceu na África. Na 
maioria dos países, quase nenhum centro de Testing and Counselling foi montado até os últimos anos. No que diz respeito ao apoio médico e social às pessoas doentes, só algumas operações pontuais foram empreendidas - mas nada que possa responder à altura o desafio! Isso foi resultado não só da pobreza extrema de quase todos esses países, mas também de uma política acintosamente concebida pelas organizações internacionais e pelos países ricos, que continuaram a afirmar a possibilidade de se deter a progressão da epidemia simplesmente graças às campanhas de informação e à distribuição de preservativos ${ }^{13}$.

Nessas condições, todas as informações dramáticas que foram derramadas nas populações deixavam-nas sem qualquer perspectiva de que cada pessoa pudesse conhecer seu estado sorológico, receber conselhos adaptados a sua situação pessoal e tomar decisões idôneas. Além disso, nenhuma esperança de apoio caso ela fosse soropositiva ou doente. Tal situação só abre portas para o que se pode chamar de uma fuga para o imaginário.

Muitos trabalhos antropológicos de alta qualidade foram realizados sobre essas questões ${ }^{12,14}$. Eles mostraram a realidade e a profundidade das dinâmicas de construção de sentido que vêm se operando, nas comunidades africanas, em torno do choque terrível que constitui a epidemia da aids. Mas tiveram pouco impacto sobre a organização concreta da luta. Uma das razões é a dificuldade persistente para superar as fronteiras disciplinares.

O que diz o antropólogo diante de situações desse tipo? A realidade humana não pode ser reduzida a uma simples racionalidade geométrica e material. As dinâmicas do espírito humano têm dimensões coletivas que são inseparáveis, tanto de um patrimônio cultural às vezes antigo, quanto do próprio movimento de transformações do mundo de hoje. Tentar reduzir o comportamento humano a modelos simplificadores não resolve nada. As disciplinas que buscam soluções rápidas e simples para resolver problemas urgentes têm dificuldades para aceitar essa fala. Elas se queixam de que os antropólogos, em vez de ajudar a achar soluções, tornam as coisas ainda mais complexas. Mas não são necessariamente os antropólogos que são complicados (eles às vezes o são, eu admito), é a própria realidade que é complicada. A experiência ensina que simplificá-la artificialmente nunca dá certo.

\section{Os sujeitos sociais, atores de sua situação de vida}

Além da análise da dinâmica das representações sociais, há um outro domínio no qual a antropologia pode contribuir para participar da resolução de problemas de saúde. Quero falar das relações entre dimensões coletivas e ação individual, e do seu papel nos processos de construção da realidade na existência cotidiana. Para desenvolver esse assunto, vou me basear em dois estudos interdisciplinares que conduzimos em dois lugares diferentes : uma cidade na África e outra aqui no Brasil.

Os objetivos desses dois estudos, conduzidos com dez anos de intervalo - em 1985 na África e em 1995 no Brasil -, foram o estudo das relações entre as desigualdades socioeconômicas e a variabilidade no estado de saúde. Bem se sabe que o problema das disparidades de saúde constitui um dos grandes desafios das políticas públicas de saúde. Isso é verdade nos países mais desenvolvidos - Europa, Estados Unidos, Japão onde, apesar da melhoria global do nível de saúde, as diferenças de morbidade e mortalidade entre as categorias sociais e as regiões permanecem muito marcantes. Éainda mais pertinente no que diz respeito aos países emergentes e aos países pobres. Não é necessário ressaltar aqui a importância do tema das desigualdades socioeconômicas em um país como o Brasil, que chegou a ser chamado de Belíndia porque reunia situações de saúde semelhantes àquelas encontradas na Bélgica e àquelas encontradas na Índia. Achar respostas para situações de pobreza e desigualdades extremas - com sua expressão mais evidente no domínio da saúde - é, com certeza, um dos maiores desafios que o 
Brasil enfrenta. No país da África onde conduzimos nossa outra pesquisa - o Niger, país limítrofe do deserto do Saara - a situação é distinta, pois a miséria é um problema geral. Na classificação do Banco Mundial, ele consta agora como um dos países mais pobres do mundo. Apesar disso, existem desigualdades: há quem tenha conseguido melhorar suas condições de vida a ponto de ir além da satisfação de suas necessidades básicas, e há quem consegue apenas sobreviver.

O estudo foi conduzido em 1985 na cidade de Maradi, na parte central do Niger, cuja população alcançava nessa época cerca de 85.000 habitantes ${ }^{15-17}$. A economia assentava-se principalmente sobre o comércio com o grande país vizinho, a Nigéria, e sobre o comércio dos produtos agrícolas oriundos das regiões rurais circunvizinhas. O estudo foi voltado principalmente para a saúde das crianças com menos de 5 anos de idade. Ele incluiu, no quadro de uma colaboração interdisciplinar estreita, investigações socioeconômicas conduzidas por geógrafos econômicos, enquêtes epidemiológicas e estudos antropológicos aprofundados.

As investigações foram conduzidas em uma amostragem representativa da população da cidade. Elas permitiram, em um primeiro passo, dividir as famílias em quatro estratos econômicos, em função de indicadores descritivos das suas condições materiais de vida: índice de bens. Isso conduziu, particularmente, ao isolamento de dois extremos: uma pequena burguesia emergente que tinha rendas e condições de moradia mais que suficientes para atender suas necessidades básicas e, por outro lado, populações que viviam em condições de precariedade extrema: palhoças muito precárias, sem água, saneamento ou luz.

Foram realizadas observações clínicas nas crianças das famílias pertencentes aos vários estratos. Doenças do aparelho respiratório, parasitoses, doenças da pele, e estado nutricional foram observados em cada criança. 527 crianças, distribuídas entre 450 famílias, foram assim observadas. O estudo confirmou a existência de diferenças marcantes conforme o nível socioeconômico para quase todos os critérios utilizados. Entretanto, os resultados trouxeram uma grande surpresa: havia pouca diferença no que dizia respeito ao estado nutricional das crianças dos estratos mais altos e dos mais pobres. Até mesmo entre aquelas da pequena burguesia e aquelas das famílias que moravam em condições péssimas. Este paradoxo era o resultado do conjunto de dois fenômenos contrários:

- as crianças das famílias ricas não aproveitavam tanto quanto se podia esperar as boas condições de vida dos pais;

- as crianças das famílias miseráveis apresentavam um estado nutricional médio melhor do que supunha a precariedade extrema do seu quadro de vida material. Foi em cima desse paradoxo que se mobilizaram os estudos antropológicos. Para simplificar ao extremo, posso resumir assim os resultados obtidos:

- Os padrões alimentares das famílias mais ricas permaneciam seguindo os modelos tradicionais, de modo que, apesar de comerem mais, suas crianças não desfrutavam de uma melhor qualidade de comida.

- A pobreza das condições de moradia e de vida material dos mais pobres não refletia os meios pelos quais eles conseguiam acesso à alimentação cotidiana. Simplificando muito, vamos dizer que eles se inseriam dentro de redes de doações de alimento, redes muito vívidas na sociedade local. Eles obedeciam em primeiro lugar a objetivos sociais - manter laços sociais, mostrar sua generosidade mas funcionavam também como instituições locais de proteção social. Participar dessas redes - recebendo muito mais do que elas davam - era, para as mães, um meio de conseguir comida para elas próprias e para suas crianças. Nessas condições, a criação de relações sociais e a inserção em redes de troca abastecidas por pessoas mais ricas, ocupavam uma posição central nas estratégias de sobrevivência das famílias pobres. A eficiência dessa estratégia foi evidenciada nesse estudo pelo fato de as crianças das mães 
que participavam ativamente nessas redes terem um estado nutricional expressivamente melhor que o daquelas que ficavam de fora.

Inicialmente, pensávamos que uma situação dessas estava estreitamente ligada às realidades especificas da cultura africana local. Foi com uma certa idéia comparativa que montamos, 10 anos depois, em um contexto brasileiro, um estudo mais ou menos semelhante no que se refere a alguns de seus aspectos. Este estudo foi conduzido em 1995, em Paranaguá, cidade paranaense que contava nessa altura com 110.000 habitantes. Pequena cidade para os padrões brasileiros, mas cujo tamanho permitia aplicar uma metodologia semelhante àquela utilizada no Niger: quer dizer, conduzir um estudo global da cidade e montar uma amostragem representativa da população total. Paranaguá apresenta uma realidade social, cultural, econômica e ecológica totalmente diferente daquela encontrada em Maradi - no Niger. Um grande porto, uma atividade econômica bastante alta, uma taxa de desemprego elevada - mas sem comparação com a que se encontrava na cidade africana - e um clima muito mais ameno do que aquele à beira do grande deserto do Saara.

A metodologia aplicada neste caso para descrever as desigualdades socioeconômicas e relacioná-las à variabilidade do estado de saúde foi bastante semelhante àquela montada em Maradi $^{2,18}$. O trabalho de campo foi realizado por doutorandos do Doutorado em Meio Ambiente e Desenvolvimento da UFPR e da Universidade de Bordeaux 2 (França). As enquêtes epidemiológicas foram feitas pela Doutora Eleusis Ronconi de Nazareno ${ }^{* 19}$; e as investigações antropológicas pela Doutora Tatiana Engels Gerhardt ${ }^{*} 20$.

A estratificação foi feita em função de elementos do quadro de vida, adaptando os critérios utilizados à realidade local. O resultado mostrou, nesse caso também, grandes desigualdades. Os moradores se encontravam particularmente nas franjas mais po- bres das cidades, repelidos nas áreas de manguezais em condições de grande insalubridade, com uma taxa de desemprego ou de emprego informal muito elevada. Por outro lado, tinham populações de alta renda, morando em geral perto do centro da cidade, em habitações de alto padrão e desfrutando de todos os itens do conforto moderno.

Exames clínicos foram aplicados a 391 crianças, com uma atenção particular às parasitoses, às doenças da pele e ao estado nutricional.

Mais uma vez, a intensidade das diferenças de estado de saúde conforme o nível econômico da família e o local de moradia foi confirmada por varias patologias.

Mas em Paranaguá, com uma certa semelhança com o observado em Maradi, as diferenças notadas no que diz respeito ao estado nutricional das crianças foram menos marcadas do que se esperava e, antes de tudo, as prevalências da malnutrição aguda e da malnutrição crônica não atingiram os níveis que podiam ser esperados nas famílias submetidas a condições de vida particularmente precárias, seja por morarem nas franjas mais insalubres da cidade ou por pertencerem ao estrato econômico mais baixo.

Os estudos antropológicos conduzidos em Paranaguá evidenciaram, por parte destas famílias pobres, a existência de estratégias de acesso aos recursos alimentares bastante semelhantes àquelas observadas no Niger: integração a redes de circulação e distribuição de comida, busca de proteção. As estruturas sociais utilizadas e as estratégias desenvolvidas são diferentes, em Paranaguá o papel principal sendo desempenhado pelas relações familiares e de vizinhança, a integração com redes de solidariedade organizadas em torno das igrejas, a integração em redes sociais e políticas de clientelismo que podem dar acesso a cestas básicas.

Apesar das diferenças entre as duas situações estudadas, a lógica global é a mesma. Ela mostra que as populações mais pobres 
não são objetos passivos das desigualdades. Elas buscam respostas, desenvolvem estratégias. Permanecem como atores sociais, mobilizando os recursos materiais e sociais disponíveis para resolver os problemas encontrados.

Esses dois estudos conduzem ao questionamento da noção de "condições de vida", considerada nas suas relações com as disparidades de saúde ${ }^{21}$. Sem dúvida, cada indivíduo, cada família, cada grupo local, está enfrentando, na sua existência cotidiana, não apenas restrições e potencialidades referentes a seu quadro de vida material, mas também aquelas que têm sua origem em seu universo social e cultural: representações e valores transmitidos pela educação e pelos processos de socialização, e a configuração de relações interpessoais decorrentes da organização social e dos embates de poder. Seu estado de saúde está necessariamente na dependência desse contexto, refletindo a posição que ele ocupa dentro da estrutura social e econômica da sociedade. No entanto, cada um - indivíduo, família, grupo local - conserva um espaço de atuação próprio que lhe permite intervir como ator da sua própria existência: reinterpretando as condições externas às quais ele é submetido e elaborando o que nós propomos chamar de "situação de vida", essa realidade existencial cotidiana à qual ele impõe, com mais ou menos força conforme os casos, o seu cunho. Ele elabora assim, no decorrer da sua história pessoal, sua própria experiência de sujeito: consciência e olhar distanciado sobre o que cabe em torno dele, tanto no domínio do material como do imaterial.

Qual o interesse desse tipo de observação em termo de ações de saúde? Pode-se dizer que se trata aqui apenas de estratégias de sobrevivência desenvolvidas pelas categorias sociais mais carentes. Elas não vão mudar em nada as causas profundas das desigualdades e das injustiças. É claro que, por si mesmas, elas não podem mudar nada em sistemas sociais cuja própria estrutura é geradora de pobreza.

Mas quanto tempo faz que se pretende mudar as estruturas globais para resolver os problemas do cotidiano? Até agora, os resultados foram pouco conclusivos! Será que não existe outra possibilidade, além de apenas conceber soluções de fora e desenvolver uma oferta que se pretende ser adequada às necessidades dos usuários - tais como aquelas definidas a partir do saber dos peritos?

Se, ao contrário, fosse aceita a idéia de que as pessoas às quais estão dirigidas as políticas públicas, até as categorias mais carentes, não são passivas, que elas mesmas atuam no dia a dia para procurar soluções, isto abriria a possibilidade de uma outra linha de desempenho da ação pública no domínio da saúde - uma linha construída não exclusivamente sobre um saber vindo de cima para baixo, mas negociada a partir da própria experiência das pessoas e das comunidades.

É claro que há muitos obstáculos sociais e políticos para operar essa reconversão. Mas os primeiros obstáculos que temos de superar são aqueles que encontramos no quadro da nossa própria atuação de cientistas. Temos que aceitar a idéia de que as "populações”, em geral consideradas como objetos de estudo, são também sujeitos, atores que têm sua própria experiência dos problemas que pretendemos resolver. Se eles são sujeitos, temos que considerá-los como parceiros. Até nas situações mais desesperadas - como no caso dessas populações miseráveis do Niger - eles lutam para construir um futuro. Para esperar conseguir um dia convencer os políticos, nós cientistas temos que construir uma outra relação com nossos “objetos de estudo".

Diante dos problemas que encontramos no campo da promoção da saúde, a colaboração entre disciplinas sociais e médicas é uma necessidade imprescindível. A complexidade do real não pode ser abordada a partir de apenas um ângulo ou de um nível de análise. É necessário juntar os olhares e as competências.

Através de alguns exemplos, tentei mostrar nesta palestra o que a Antropologia pode trazer em uma colaboração com a saúde pública e a epidemiologia. Isto pode ser resumido em poucas palavras simples: uma 
visão mais próxima da realidade da vida dessas pessoas, desses grupos que muitas vezes desaparecem atrás do apelido genérico de "populações". Adotar esta postura conduz ao reconhecimento de duas feições essenciais do social:

- O fato de os seres humanos e as sociedades que eles constituem serem produtores de sentido. A busca de sentido é um dos fatores mais determinantes nos comportamentos, tanto no plano indivi- dual como no coletivo. Qualquer política que aborde as "populações" como simples consumidoras de cuidados corre grande risco de fracasso.

- O fato de as "populações" serem sempre constituídas de atores, de sujeitos que, por pior que seja a sua situação, estão sempre procurando soluções; sujeitos que temos de considerar como parceiros, tanto na produção do saber como na elaboração de programas de ação.

\section{Referências}

1. Zanoni M., Raynayt Cl. Meio ambiente e desenvolvimento: imperativos para a pesquisa e a formação Cad Des e Meio Ambiente nº 1. UFPR; 1994. p. 143-66.

2. Raynaut $\mathrm{Cl}$., Processo de Construção de um programa interdisciplinar de pesquisa no quadro do Doutorado em Meio Ambiente e Desenvolvimento (MAD, UFPR), Cad Des e Meio Ambiente no 3. UFPR; 1996. p. 23-34.

3. U.S. Census Bureau, Recent HIV Seroprevalence levels by country, Research Note n 27; 2002.

4. ONUSIDA. Global Estimates of the HIV/AIDS Epidemic as of end 1999; 2000 (www.unaids.org/ epidemic).

5. OMS, Epidemiological Fact Sheet on HIV/AIDS and sexually transmitted diseases. Côte-d'Ivoire; 1998.

6. Raynaut $\mathrm{Cl}$, Muhongayire F. Chroniques d'une mort annoncée : problèmes d'éthique et de méthode posés par l'application de la démarche anthropologique au suivi de familles touchées par le sida (à partir du cas rwandais). In: Dozon J-P, Vidal L (eds.) Les sciences sociales face au sida en Afrique. Paris: ORSTOM; 1993.

7. Raynaut $\mathrm{Cl}$. Comment évaluer les politiques publiques de lutte contre le sida en Afrique, in: Baré J-F (éd.). L'évaluation des politiques de développement. Approches pluri-disciplinaires. Paris: L'Harmattan; 2002.

8. Cleveland J, Ferry B (eds). Sexual Behaviour and AIDS in the Developing World, Londres: Taylor and Francis; 1995.

9. Raynaut Cl. Afrique et sida: tradition et changement, Sciences Sociales et Santé 1996: Vol 4 (2).
10. Raynaut $\mathrm{Cl}$. Contexte social et dynamique de l'épidémie de sida en Afrique: tradition et changement. In: Le sida en Afrique, Recherches en Sciences de l'Homme et de la Société. Paris: ANRS/ ORSTOM; 1997.

11. Raynaut Cl. L'Afrique et le sida: questions à l'Anthropologie, l'Anthropologie en question, Sciences Sociales et Santé 1997: Vol 15 (2).

12. Coll. Sciences sociales et sida en Afrique. Paris -Dakar: ORSTOM, CODESRIA, AUPELF, UREF (publicação CDrom); 1997.

13. Lavollay M. Quand USAID et GPA s'opposaient au dépistage conseil. Le Journal du sida 1996: 86-7, 61-2; 1996.

14. Dozon J-P, Vidal L (eds.), Les sciences sociales face au sida en Afrique. Paris: ORSTOM; 1993 - Réédition 1995.

15. Raynaut Cl., Disparités et homogénéité à Maradi (Niger): la santé comme révélateur d'une réalité urbaine. In: Coll. Pauvreté et développement dans les pays tropicaux. Bordeaux: Presses Universitaires de Bordeaux; 1988.

16. Raynaut $\mathrm{Cl}$. Approches sociales de l'alimentation infantile en milieu urbain Africain (Guide méthodologique). L'Enfant en Milieu tropical, 201. Paris: Centre International de l'Enfance; 1992 (versão inglesa, 1992).

17. Raynaut $\mathrm{Cl}$. Se nourrir en ville: stratégies économiques et pratiques sociales (le cas de Maradi, Niger). In: Ch. Blanc-Pamard éd. La santé en société. Regards et remèdes. Collection Colloques et Séminaires. Paris: ORSTOM; 1993. 
18. Canapero S. C., Gerhardt T., Nazareno E. R., et al, Espaço urbano, situações de vida e saúde na cidade de Paranaguá; relato preliminar de uma prática interdisciplinar, Cad Des e Meio Ambiente $\mathrm{n}^{\circ}$ 3: UFPR; 1996. p. 35-48.

19. Nazareno E. Condições de vida e saùde infantil: Heterogeneidades espaciais e desigualdades sociais na cidade de Paranagua, Thèse de doctorat, Doutorado em Desenvolvimento e Meio Ambiente, Curitiba, Universidade Federal do Paraná, 1999.
20. Gerhardt ET. Anthropologie et Santé Publique: approche interdisciplinaire. Pauvreté, situations de vie et santé au quotidien à Paranaguá, Paraná, Brésil. [Thèse de Doctorat en Anthropologie], Bordeaux: Université de Bordeaux 2; 2000.

21. Raynaut Cl, Gerhardt ET, Nazareno TE. Pauvreté, inégalités économiques et disparités de santé: conditions de vie et stratégies d'acteurs, Face a Face, Revista eletrônica: www.ssd.u-bordeaux2.fr (versões francesa e inglesa); 2002. [março 2002] 